\title{
INVESTIGATORY PROFILE AND TREATMENT OUTCOME OF PAEDIATRIC SCRUB TYPHUS PATIENTS: A TERTIARY CARE HOSPITAL EXPERIENCE IN SOUTHERN INDIA
}

\author{
D. Ramaganeshan ${ }^{1}$, P. Ramu2 ${ }^{2}$ S. V. Ramesh ${ }^{3}$, N. Chaitanya ${ }^{4}$
}

${ }^{1}$ Associate Professor, Department of Paediatrics, King George Hospital, Andhra Medical College, Visakhapatnam. ${ }^{2}$ Assistant Professor, Department of Paediatrics, King George Hospital, Andhra Medical College, Visakhapatnam. 3 Junior Resident, Department of Paediatrics, King George Hospital, Andhra Medical College, Visakhapatnam. 4Junior Resident, Department of Paediatrics, King George Hospital, Andhra Medical College, Visakhapatnam.

\section{ABSTRACT}

\section{BACKGROUND}

Scrub typhus (Tsutsugamushi fever) is a zoonotic disease among Rickettsial infections, wherein man is an accidental host. Scrub typhus is an important and widespread cause of acute febrile illness in rural areas of Asian and Northern Australia. In the preantibiotic era, the mortality rates as high as $42 \%$ were reported. Scrub typhus is very responsive to treatment with timely and appropriate antibiotics. The disease still causes a significant rise of death in rural areas, where effective treatment is unavailable or delayed. Scrub typhus is grossly underdiagnosed, especially in India due to lack of awareness among clinicians and also due to lack of diagnostic tests. In our study, we studied the investigatory profile and treatment outcome in paediatric Scrub typhus patients.

\section{MATERIAL AND METHODS}

This cross-sectional study was conducted at King George Hospital (a tertiary care teaching hospital) Visakhapatnam, Andhra Pradesh between July 2013 and November 2015. All paediatric patients presented with acute febrile illness and tested positive onestep Scrub typhus antibody test is included in the study. Children with mixed infections are excluded from the study.

\section{AIM}

The study was conducted to find out the investigatory profile (namely WBC count, platelet count, CRP, ESR, LFT, serum creatinine, serum electrolytes, chest X-ray and CSF analysis) and to determine the outcome of treatment in paediatric Scrub typhus patients.

\section{RESULTS}

In the present study out of 93 children $<12$ years' age group who are tested positive for Scrub typhus antibody test, 38 patients (40.86\%) had leucocytosis, 6 patients $(6.45 \%)$ had leucopenia and 49 patients $(52.69 \%)$ had thrombocytopenia. Majority of our patients had defervescence by $24-48$ hours of treatment; $56.9 \%$ of patients (53) had their duration of hospital stay up to 10 days. Out of 93 patients two patients had ARDS picture, one patient had acute renal failure requiring dialysis and one died of ARDS (Acute Respiratory Distress Syndrome).

\section{CONCLUSION}

The present study has thrown light regarding the investigatory profile, therapeutic options for the wide range of complications and outcome in paediatric Scrub typhus patients.

\section{KEYWORDS}

Scrub Typhus, Orientia Tsutsugamushi, Paediatric Patients, One-Step Scrub Typhus Antibody Test, Investigatory Profile.

HOW TO CITE THIS ARTICLE: Ramaganeshan D, Ramu P, Ramesh SV, et al. Investigatory profile and treatment outcome of paediatric scrub typhus patients: a tertiary care hospital experience in Southern India. J. Evolution Med. Dent. Sci. 2016;5(67):47934796, DOI: $10.14260 /$ jemds/2016/1092

\section{INTRODUCTION}

Hippocrates in $460 \mathrm{BC}$ used the term typhus, meaning 'smoke,' to describe the 'confused state of the intellect - a tendency to stupor associated with high fevers. ${ }^{\prime}$ ' Approximately 1 million infections occur each year and it is estimated that more than 1 billion people are at risk. Scrub typhus occurs mostly in Asia including areas delimited by Korea, Pakistan and Northern Australia. Most infections in children are acquired in rural

Financial or Other, Competing Interest: None.

Submission 10-06-2016, Peer Review 28-07-2016,

Acceptance 02-08-2016, Published 20-08-2016.

Corresponding Author:

Dr. P. Ramu,

Raja Sagi Residency, FF-3,

Door No: 14-1-122/13,

Nowroji Road, Maharanipeta,

Visakhapatnam-530002, A. P.

E-mail:drpramu73@gmail.com

DOI: $10.14260 /$ jemds/2016/1092 areas. In Thailand and Sri Lanka, Scrub typhus is the cause of $1-8 \%$ of acute fevers of unknown origin. Infections are most common during rainy months, usually June through November. Leukocyte and platelet counts are most commonly within normal ranges, although thrombocytopenia, leucocytosis, elevated liver enzymes, hyponatremia, leucopenia are common to rickettsial infections.

\section{MATERIAL AND METHODS}

This cross-sectional study was conducted at King George Hospital (a tertiary care teaching hospital) Visakhapatnam, Andhra Pradesh between July 2013 and November 2015. Children less than 12 years' age group presented with acute febrile illness and tested positive for one-step Scrub typhus antibody test are included in the study. All these children were investigated for the routine blood counts, liver function tests, chest X-ray, CRP, ESR and electrolytes. In our study, we had 8 patients presented with meningoencephalitis like picture and 
hence we studied the CSF picture in these patients. Children with mixed infections are excluded from the study.

\section{RESULTS}

In our study, we included 93 children tested positive for onestep Scrub typhus antibody test while investigating for acute febrile illness. All these children were brought from rural areas of nearby districts. In our study 49 patients (52.69\%) had normal WBC count, 39 patients (41.94\%) had normal platelet count, 38 patients (40.86\%) had leucocytosis, 49 patients $(52.69 \%)$ had thrombocytopenia, 12 patients $(12.9 \%)$ had elevated serum creatinine, 32 patients $(34.40 \%)$ had increased SGOT, 21 patients (22.58\%) had increased SGPT levels and 5 patients had dyselectrolytemia. Out of the 5 patients, 3 had hyperkalaemia and mild hyponatremia in 2 of our patients (Table 1, 2).
Out of the 93 patients, 8 patients presented with meningoencephalitic picture and underwent CSF analysis; 5 out of these patients have CSF pleocytosis with lymphocyte predominance (Table 3). Majority of our patients (55.9\%) had defervescence at 24-48 hours of admission (Table 5) with the treatment protocol we followed (Table 4).

Coming to the duration of hospital stay in our study population, $56.9 \%$ (53 patients) had up to 10 days of hospital stay (Table 6). Since ours is a tertiary care referral hospital for the surrounding 3-4 districts, all of our patients presented to us beyond first week of illness after having been treated in the periphery for common acute febrile illnesses. Out of 93 patients one developed renal failure requiring dialysis, 2 developed ARDS requiring ventilation of whom one died (Table 7).

\begin{tabular}{|c|c|c|c|c|c|c|c|c|c|}
\hline $\mathbf{n = 9 3}$ & $\begin{array}{c}\text { WBC } \\
\text { Count }\end{array}$ & Platelet Count & CRP & ESR & S. Creatinine & S. Bilirubin & SGOT & SGPT & Electrolyte Derangement \\
\hline Normal & 49 & 39 & 72 & 78 & 81 & 75 & 61 & 72 & 88 \\
\hline Increased & 38 & 5 & 21 & 15 & 12 & 18 & 32 & 21 & $\uparrow \mathrm{K}^{+-} 3$ \\
\hline Decreased & 6 & 49 & - & - & - & - & - & - & $\downarrow \mathrm{Na}^{+}-2$ \\
\hline \multicolumn{8}{|c|}{ Table 1: Laboratory Investigatory Profile } \\
\hline
\end{tabular}

\begin{tabular}{|c|c|c|}
\hline Parameter & $\begin{array}{c}\text { Number of } \\
\text { Cases ( } \mathbf{n = 9 3 )}\end{array}$ & $\mathbf{\%}$ \\
\hline Leucocytosis & 38 & 40.86 \\
\hline Leucopenia & 6 & 6.45 \\
\hline Thrombocytosis & 5 & 5.38 \\
\hline Thrombocytopenia & 49 & 52.69 \\
\hline \multicolumn{2}{|c|}{ Table 2: Observed Patterns of WBC and } \\
Platelet Count in Present Study \\
\hline
\end{tabular}

\begin{tabular}{|c|c|}
\hline CSF Parameter & Number of Patients \\
\hline Normal Cell Count & 3 \\
\hline Increased (Pleocytosis) & 5 \\
\hline Differential Count (L/N) & $\mathrm{L}>\mathrm{N}-5$ \\
\hline Normal CSF Glucose & 8 \\
\hline Decreased CSF Glucose & 0 \\
\hline Increased CSF Protein & 0 \\
\hline \multicolumn{2}{|c|}{ Table 3: CSF Analysis in Present Study (n=8) } \\
\hline
\end{tabular}

\section{Abbreviations}

CSF-Cerebrospinal Fluid, L-Lymphocyte, N-Neutrophil.

\begin{tabular}{|c|c|c|c|}
\hline $\begin{array}{c}\text { Sl. } \\
\text { No. }\end{array}$ & Complications & $\begin{array}{c}\text { Number } \\
\text { of Cases }\end{array}$ & Rx Protocol Followed \\
\hline 1 & $\begin{array}{c}\text { Hepatic } \\
\text { Dysfunction }\end{array}$ & 40 & $\begin{array}{c}\text { Tab. Doxy+IVF+LFT } \\
\text { Monitoring+Paracetamol } \\
\text { for Fever+Other } \\
\text { Supportive Care }\end{array}$ \\
\hline 2 & $\begin{array}{c}\text { Renal } \\
\text { Dysfunction }\end{array}$ & 12 & $\begin{array}{c}\text { Tab. Doxy+IVF+RFT } \\
\text { Monitoring+other } \\
\text { Supportive Treatment }\end{array}$ \\
\hline 3 & Meningoencephalitis & 8 & $\begin{array}{c}\text { O2 Inhalation+Tab. Doxy } \\
\text { through NGT+Inj. } \\
\text { Ceftriaxone+Paracetamol } \\
\text { (sos) Vital signs } \\
\text { Monitoring and other } \\
\text { Supportive Treatment }\end{array}$ \\
\hline 4 & $\begin{array}{c}\text { Gastro-Intestinal } \\
\text { Bleeding }\end{array}$ & 4 & $\begin{array}{c}\text { Tab. Doxy+IVF+LFT \& } \\
\text { RFT Monitoring+IV } \\
\text { paracetamol }\end{array}$ \\
\hline
\end{tabular}

\begin{tabular}{|c|c|c|c|}
\hline & & & $\begin{array}{c}\text { (sos)+IV Antibiotics and } \\
\text { Other Supportive } \\
\text { Treatment }\end{array}$ \\
\hline 5 & $\begin{array}{l}\text { Severe } \\
\text { Anaemia }\end{array}$ & 8 & $\begin{array}{c}\text { Tab. Doxy+IVF+LFT \& } \\
\text { RFT Monitoring+IV } \\
\text { Paracetamol } \\
\text { (sos)+other Supportive } \\
\text { Treatment }\end{array}$ \\
\hline 6 & Shock & 3 & $\begin{array}{c}\text { O2 Inhalation+TPR } \\
\text { Chart/SpO2 } \\
\text { Monitoring+IV } \\
\text { Antibiotics+Inj. } \\
\text { Dopamine }(5-10 \mu \mathrm{g} / \mathrm{kg}) \\
\text { for 2-3 days+IVF+Tab. } \\
\text { Doxy } \\
\end{array}$ \\
\hline 7 & Myocarditis & 3 & $\begin{array}{c}\text { Vital \& SpO2 } \\
\text { Monitoring+2/3 IVF+Tab } \\
\text { Doxy+ Inj. Lasix }\end{array}$ \\
\hline 8 & Bronchopneumonia & 18 & $\begin{array}{c}\text { O2 Inhalation+IVF+IV } \\
\text { Antibiotics+Tab. Doxy+ } \\
\text { other Supportive Care }\end{array}$ \\
\hline 9 & $\begin{array}{l}\text { Multi-Organ } \\
\text { Involvement }\end{array}$ & 4 & $\begin{array}{l}\text { O2 Inhalation+IVF+IV } \\
\text { Antibiotics+Tab. Doxy+ } \\
\text { other Supportive Care }\end{array}$ \\
\hline 10 & Pericarditis & 1 & $\begin{array}{l}\text { O2 Inhalation+IVF+IV } \\
\text { Antibiotics+Tab. Doxy+ } \\
\text { other supportive care }\end{array}$ \\
\hline 11 & ARDS & 2 & $\begin{array}{l}\text { Ventilator Care+02 } \\
\text { Inhalation+IVF+IV } \\
\text { Azithromycin \& Broad- } \\
\text { Spectrum Antibiotics+ } \\
\text { Tab. Doxy+other } \\
\text { Supportive care }\end{array}$ \\
\hline \multicolumn{4}{|c|}{$\begin{array}{l}\text { Table 4: Treatment Protocols Followed for our } \\
\text { Paediatric Scrub Typhus Patients as Follows }\end{array}$} \\
\hline
\end{tabular}

\section{Abbreviations}

Rx-treatment, Tab-tablet; Doxy-Doxycycline (once patient can take orally); IVF-Intravenous Fluids; LFT-Liver Function Tests; RFT-Renal Function Tests; TPR-Temperature, pulse rate charts; NGT-Nasogastric Tube; Lasix-furosemide. 


\begin{tabular}{|c|c|c|}
\hline $\begin{array}{c}\text { No. of Hours Taken for } \\
\text { Defervescence after Admission }\end{array}$ & $\begin{array}{c}\text { No. of Cases } \\
\mathbf{n = 9 3}\end{array}$ & $\mathbf{\%}$ \\
\hline$<24$ hours & 0 & 0 \\
\hline 24-48 hours & 52 & 55.9 \\
\hline $48-72$ hours & 35 & 37.6 \\
\hline \multicolumn{2}{|c|}{$>$ 72 hours } & 6.5 \\
\hline Table 5: Duration for Defervescence with \\
Above Treatment in Our Study \\
\hline
\end{tabular}

\begin{tabular}{|c|c|c|}
\hline Duration of Hospital Stay & No. of Patients & $\%$ \\
\hline Up to 10 days & 53 & 56.9 \\
\hline 10-20 days & 22 & 23.7 \\
\hline$>20$ days & 18 & 19.4 \\
\hline
\end{tabular}

\begin{tabular}{|c|c|c|}
\hline Total Number of Patients & $\mathbf{9 3}$ & $\mathbf{1 0 0 \%}$ \\
\hline $\begin{array}{c}\text { Number of Children with Renal } \\
\text { Failure Requiring Dialysis }\end{array}$ & 1 & $1.08 \%$ \\
\hline $\begin{array}{c}\text { Number of Children with } \\
\text { ARDS Ventilated }\end{array}$ & 2 & $2.15 \%$ \\
\hline Number of Children Died & 1 & $1.08 \%$ \\
\hline $\begin{array}{c}\text { Table 7: Outcome of Paediatric Scrub } \\
\text { Typhus Patients in Our Study }\end{array}$ \\
\hline
\end{tabular}

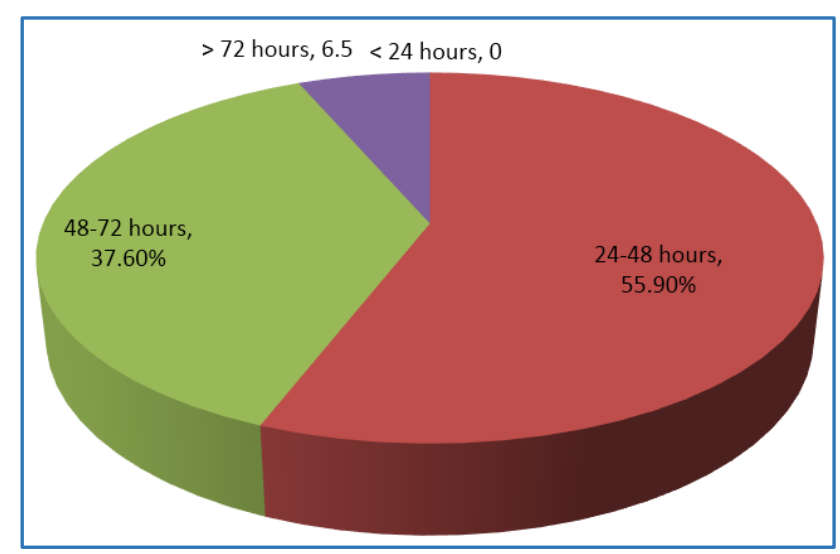

Fig. 1: Pie Diagram showing Duration for Defervescence with Treatment in Our Study

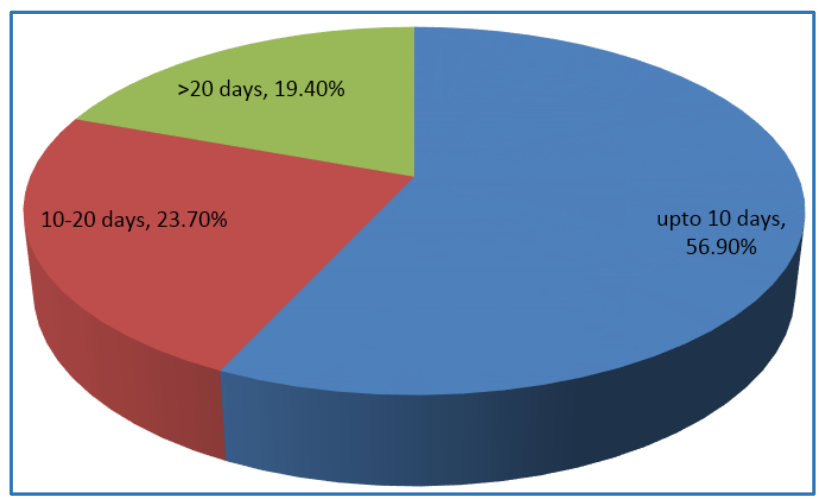

Fig. 2: Pie Diagram showing Duration of Hospital Stay in Our Study

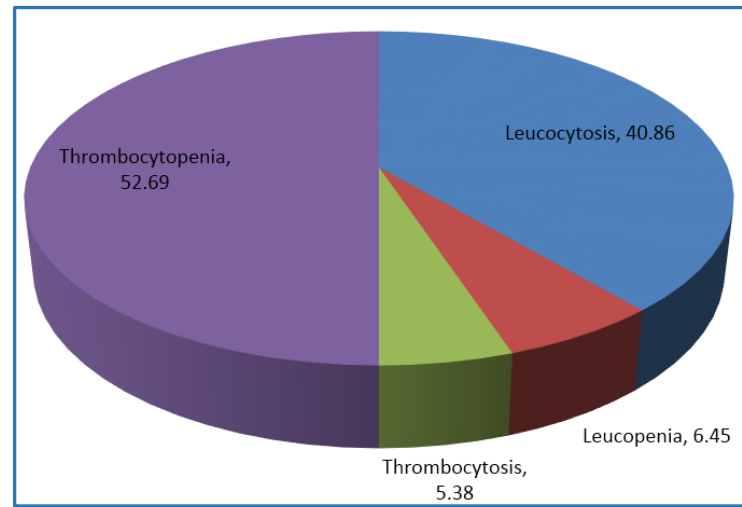

Fig. 3: Observed Patterns of WBC and Platelet Count in Present Study

\section{DISCUSSION}

Scrub typhus or Japanese river fever was known in Japanese folklore to be associated with the jungle mite or chigger, termed 'tsutsugamushi' in Japanese (tsutsuga = disease, harm, noxious and mushi $=$ bug). The term 'Tsutsugamushi disease' has been in use since 1810 to describe these fevers, but is not the only term used by the Japanese. Theobald Palm brought the first account of this disease to Europe in 1878, referring to 'Shima-Mushi' ('Island-Insect') disease. Due to lack of awareness and difficulties in diagnostics, rickettsial diseases are responsible for a substantial proportion of undiagnosed febrile illnesses in humans in many parts of the tropics. ${ }^{2}$ Following the bite of a trombiculid larval mite (Chigger), the causative organism is transmitted to humans and results in a systemic illness ranging in severity from inapparent to fatal. Recent studies suggest that the pathogenic process is stimulated by widespread infection of vascular endothelial cells, which corresponds to the distribution of disseminated vasculitic and perivascular inflammatory lesions observed in pathologic examinations. Most patients present with fever for 9-11 days (Range: 1-30 days) before seeking medical care. In addition to fever, these patients present with maculopapular rash, lymphadenopathy, hepatosplenomegaly and other gastrointestinal symptoms. A single painless eschar with an erythematous rim at the site of chigger bite is seen in 7-68\% of cases. Leukocyte and platelet counts are most commonly within normal ranges, although thrombocytopenia occurs in one-quarter to one-third of children, and leucocytosis is observed in approximately 40\%.3 Elevated liver enzymes, hyponatremia, thrombocytopenia, leucopenia or leucocytosis are common to rickettsial infections. 4,5 Cerebrospinal fluid examination shows a mild mononuclear pleocytosis with normal glucose levels. Chest radiographs reveal transient perihilar or peribronchial interstitial infiltrates in most children who are examined. ${ }^{6}$ Complications include jaundice, meningoencephalitis, myocarditis, interstitial pneumonia leading to ARDS and renal failure.7,8

The case fatality rate in untreated patients may be as high as $30 \%$, although deaths in children are uncommon. The recommended treatment regimen for Scrub typhus is doxycycline $(4 \mathrm{mg} / \mathrm{kg} /$ day PO or IV divided every $12 \mathrm{hrs}$.; maximum: $200 \mathrm{mg} /$ day). Alternative regimens include tetracycline $(25-50 \mathrm{mg} / \mathrm{kg} /$ day PO divided every $6 \mathrm{hrs}$; maximum: $2 \mathrm{~g} /$ day) or chloramphenicol $(50-100 \mathrm{mg} / \mathrm{kg} /$ day divided every $6 \mathrm{hrs}$. IV; maximum: $4 \mathrm{~g} / 24 \mathrm{hrs}$.). If used, chloramphenicol should be monitored to maintain serum 
concentrations of $10-30 \mu \mathrm{g} / \mathrm{mL}$. Therapy should be continued for a minimum of 5 days and until the patient has been afebrile for at least 3 days to avoid relapse. ${ }^{9}$

\section{CONCLUSION}

Scrub typhus is an important cause of acute febrile illness caused by Rickettsial species Orientia tsutsugamushi, presents as a systemic vasculitis like infection with wide range of clinical manifestations and often fatal complications. Though it is endemic in many parts of India, Scrub typhus is grossly underdiagnosed partly because of lack of awareness among clinicians and partly due to poor availability of standardized diagnostic tests. It needs high index of suspicion in all cases of acute febrile illness by the treating clinicians and a thorough search for the presence of eschar as well as recognition of the compatible clinical features in the patients should be made. Prompt institution of appropriate antibiotics, which results in a dramatic response can prevent serious and often lifethreatening complications. The present study has thrown light regarding the investigatory profile, therapeutic options for the wide range of complications and outcome in paediatric Scrub typhus patients.

\section{REFERENCES}

1. Llyod GR, Chadwick J, Mann WN. Hippokrates. In: Hippocrates. 2nd ed. New York: Penguin 1983.
2. Farrar J, Hotez P, Junghanss T, et al. Manson's tropical diseases. Rickettsial infections, Scrub typhus, chapter 22. 23 $3^{\text {rd }}$ ed. Elsevier publishers 2014:283-5.

3. Kliegman, Stanton, St Geme. Schor-Nelson's textbook of pediatrics, first South Asia edition. Elsevier publishers, Rickettsial infections, chapter 229, 2015:1504-5.

4. Parthasarsthy, Borker AS, Bhave SY. Partha's fundamentals of paediatrics. $2^{\text {nd }}$ ed. Jaypee brothers medical publishers (P) Ltd, Rickettsial infections. 2013;17:139-140.

5. Rathi N, Rathi A. Rickettsial infections: Indian perspective. Indian Pediatr 2010;47(2):157-64.

6. Sirisanthana V, Puthanakit T, Sirisanthana T. Epidemiologic, clinical and laboratory features of scrub typhus in thirty Thai children. Pediatr Infect Dis J 2003;22(4):341-5.

7. Tsay RW, Chang FY. Serious complications in scrub typhus. J Microbiol Immunol Infect 1998;31(4):240-4.

8. Tsay RW, Chang FY. Acute respiratory distress syndrome in scrub typhus. QJM 2002;95(2):126-8.

9. Panpanich R, Garner P. Antibiotics for treating scrub typhus. Cochrane Database Syst Rev 2002;2:CD002150. 